\title{
Expression of ADAMTS-1 mRNA in myocardium of viral heart disease mice and its clinical significance
}

\author{
HONGMEI LI ${ }^{1 *}$, YANCHUN ZHOU ${ }^{1 *}$, WEI SONG ${ }^{2}$, JIANXIU LI $^{3}$ and JINGTAO XU ${ }^{4}$ \\ Departments of ${ }^{1}$ Cardiology, ${ }^{2}$ Psychology and ${ }^{3}$ Cardiovascular Medicine, Yidu Central Hospital of Weifang, \\ Weifang, Shandong 262500; ${ }^{4}$ Weifang People's Hospital, Weifang, Shandong 261041, P.R. China
}

Received April 6, 2018; Accepted October 5, 2018

DOI: $10.3892 / e t m .2018 .6894$

\begin{abstract}
The expression of ADAMTS-1 mRNA in myocardium of viral heart disease (VHD) mice was investigated to explore its role in myocardial fibrosis. A total of 150 purebred inbred Balb/c mice were used in this study. According to the principle of similar body weight, 50 mice were selected to make an acute viral myocarditis (VMC) animal model (acute VMC group), and 50 mice were selected to make a chronic VMC animal model (chronic VMC group), and the remaining 50 mice were selected as a control group. RT-qPCR was used to detect the relative expression of transforming growth factor- $\beta 1$ (TGF- $\beta 1$ ) mRNA and ADAMTS- 1 mRNA in myocardial tissue of three groups of mice, and their relationship in myocardial fibrosis was analyzed. Compared with the control group, the collagen volume fraction (CVF) in the myocardial tissue of the acute VMC group was significantly increased, and the increase of CVF in the myocardial tissue of the chronic VMC group was the most significant $(\mathrm{p}<0.001)$. Compared with the control group, the relative expression of TGF- $\beta 1$ mRNA and ADAMTS- 1 mRNA in myocardial tissue of the mice in the acute and chronic VMC group were significantly increased $(\mathrm{p}<0.001)$. The relative expression of TGF- $\beta 1$ mRNA and ADAMTS-1 mRNA in myocardial tissue of chronic VMC group was significantly higher than that of acute VMC group $(\mathrm{p}<0.001)$. Pearson's correlation test results showed that ADAMTS-1 mRNA was positively correlated with CVF and TGF- $\beta 1$ mRNA, and the correlation coefficients were $(\mathrm{r}=0.351, \mathrm{p}<0.01, \mathrm{r}=0.401, \mathrm{p}<0.01)$. ADAMTS- 1 is involved in the occurrence and development of myocardial fibrosis, and it is positively correlated with CVF and TGF- $\beta 1$. It may play a role in promoting myocardial fibrosis during the
\end{abstract}

Correspondence to: Dr Jingtao Xu, Weifang People's Hospital, 151 Guangwen Street, Weifang, Shandong 261041, P.R. China

E-mail: uuj582@163.com

*Contributed equally

Key words: viral heart disease, viral myocarditis, ADAMTS-1 mRNA, transforming growth factor- $\beta 1 \mathrm{mRNA}$ development of VHD. It can be used as a biological index for predicting myocardial fibrosis.

\section{Introduction}

Cardiovascular disease is one of the main causes of human death. Viral heart disease (VHD) is a cardiovascular disease caused by viral infection (1). Viral myocarditis (VMC) is the main cause of serious cardiac arrhythmias, acute heart failure, and cardiogenic shock in patients with heart disease. Some patients will also develop DCM and eventually require heart transplantation (2). Studies have shown that $25-50 \%$ of VMCs are associated with viral infections. A total of $>20$ viral infections can induce VMC, and coxsackievirus $\mathrm{B} 3$ (CVB3) is the most common source of VMC infection. (3). There are many clinical manifestations of acute VMC, such as arrhythmia, atrial fibrillation and atrioventricular block, and severe sudden death can occur; the prognosis of most acute myocarditis is better, but there is a small section that of disease that undergoes transition to chronic VMC. With progress of the disease, acute and chronic VMC will have different degrees of myocardial fibrosis at all stages, and myocardial fibrosis is the main pathological basis for the development of multiple complications of VMC and myocarditis to cardiomyopathy (4).

Myocardial fibrosis is the change of collagen fiber composition in the normal tissue structure of cardiac myocardium fibers, and changes in the proportion of different collagen components, resulting in a large number of deposition of collagen fibers, resulting in disordered collagen metabolism, causing pathological changes in myocardium (5). Transforming growth factor- $\beta 1$ (TGF- $\beta 1$ ) is a recognized profibrotic cytokine, a growth factor most closely related to myocardial fibrosis, and plays an important role in the process of fibrosis in various organs (6). ADAMTS-1 is a newly discovered metalloprotease with proteolytic activity in recent years, and is one of the major members of the metalloprotease family (7). ADAMTS-1 is widely distributed and expressed in mammalian tissues and organs. It participates in the pathological process of atherosclerosis and neuropathic injury, and it is associated with arterial remodeling (8).

At present, the relationship between ADAMTS-1 and VMC has not been studied. This study investigated the role of ADAMTS-1 in myocardial fibrosis of VMC by observing 
the expression of ADAMTS-1 in myocardial tissue of VMC mouse model in order to provide clinical reference.

\section{Materials and methods}

Experimental animals. A total of 150 purebred inbred Balb/c mice, 3-7 weeks of age, body weight 15-23 g were purchased from Model Organisms [license no. SCXK (Shanghai) 2005-0002; Shanghai, China]. The mice were kept in a clean environment with an indoor temperature of $22-26^{\circ} \mathrm{C}$ and a humidity of $52-58 \%$. Standard cages were used, with 5 mice in each cage. The mice were maintained in a $12 \mathrm{~h} \mathrm{light/dark}$ cycle, and were allowed free access to food and water. This animal study was approved by the Yidu Central Hospital of Weifang Ethics Committee (Weifang, China).

Virus preparation. The CVB3 Nancy strain (Virus Research Institute of Wuhan University Medical College, Wuhan, China) was passaged in HeLa cells (Shanghai Gefan Biotechnology Co. Ltd., Shanghai, China). After the cells grew to form a confluent monolayer, the culture fluid was discarded and washed twice with D-Hank's solution, and the virus was diluted and added to the cells, and the supernatant was discarded after adsorption at $37^{\circ} \mathrm{C}$ for $1 \mathrm{~h}$. The supernatant was then supplemented with $2 \%$ calf serum cell culture medium, and cultured in an incubator at $37^{\circ} \mathrm{C}$ to establish a normal cell control to observe the cytopathogenic condition. Diseased and normal cells were harvested at $24-48 \mathrm{~h}$ with cell lesions $>50 \%(++)$, and were frozen at $-20^{\circ} \mathrm{C}$. Diseased and normal cells were separated by repeated freezing and thawing twice to completely release the virus particles. The samples were centrifuged at $4^{\circ} \mathrm{C}$ and $1,006.2 \times$ g for $30 \mathrm{~min}$. The supernatant was obtained and stored at $-40^{\circ} \mathrm{C}$. Selected sensitive cell lines were placed in tissue culture wells for culture, and maintenance solutions were diluted and added to culture wells, incubated at $37^{\circ} \mathrm{C}$, and cytopathological conditions were observed by using a microscope (Olympus Corporation, Tokyo, Japan). One week later, Reed and Muench method was used to calculate the concentration of $10^{5} \mathrm{TCID}_{50} \mathrm{CVB} 3$, and the sample was restored for further use.

Animal model establishment. Of the total $150 \mathrm{Balb} / \mathrm{c}$ mice, based on the principle of similar body weight, 50 mice were selected to establish an acute VMC animal model (acute VMC group), 50 mice were selected to establish chronic VMC animal model (chronic VMC group), and the remaining 50 mice were selected as control group. The mice in the acute and chronic VMC groups were sterilized at the injection site, and the asepsis inoculation concentration was $10^{5} \mathrm{TCID}_{50} / 0.1 \mathrm{ml}$ CVB3 $0.1 \mathrm{ml}$. After being fed for 7 days, an acute VMC animal model was established. In the chronic VMC group, the same CVB3 was inoculated intraperitoneally every month after the first vaccination. The monthly dose was gradually increased by $0.07 \mathrm{ml}$. After 3 months, a chronic VMC animal model was established. The control group was injected with virus-free EMEM at the same time. The number of the mice that died was counted. The mice were sacrificed by decapitation 7 days and 3 months after the completion of the modeling. A portion of the myocardium was removed and quickly placed in liquid nitrogen, and stored at $-80^{\circ} \mathrm{C}$ until use.
Determination of myocardial collagen in mice. Myocardial tissue was taken to prepare paraffin sections and refer to the staining methods reported by Rittié (9) to perform picrosirius red collagen stain to observe myocardial fibrosis changes. Collagen volume fraction (CVF, \%): myocardial tissue microscopy was performed by using a T1-T2-200V-200VS optical microscope (Olympus Corporation). Each section was randomly selected from 10 fields for microscopy. The myocardium was yellow, and the collagen tissue was red. Pictures were taken with the Leica camera system (Leica Microsystems, Ltd., Shanghai, China), and QWin image analysis system [Keyence (China) Co., Ltd., Shanghai, China] was used for calculating the percentage of collagen in each field of view, and the mean number represented CVF (\%), which was the severity of myocardial interstitial fibrosis.

$R T-q P C R$ detection. Total RNA extraction: the myocardial tissue cryopreserved at $-80^{\circ} \mathrm{C}$ was obtained, and TRIzol reagent [Thermo Fisher Scientific (China) Co.Ltd.] was used to lyse the solution after shaking for $30 \mathrm{~min}$ at room temperature. The extraction process was strictly in accordance with the manufacturer's protocol. The absorption value of RNA was measured by using an Ultrospec III ultraviolet spectrophotometer (Eppendorf, Hauppauge, NY, USA), and the purity of the total RNA was measured on a $1 \%$ agarose gel power supply. RT-qPCR assay was performed by using TGF- $\beta 1$, ADAMTS-1 fluorescence quantitative PCR kit (Biomiga, Inc., San Diego, CA, USA). RT reaction (reaction volume $18.6 \mu \mathrm{l}$ ): RNA $10 \mu \mathrm{l}$ and oligo(dT) $1.3 \mu \mathrm{l}$ was added to thin-walled tubes to mix well, and heated at $65^{\circ} \mathrm{C}$ for $30 \mathrm{~min} ; 7.3 \mu \mathrm{l}$ Mix liquid (with $2.3 \mu \mathrm{l}$ dNTP, $4.0 \mu \mathrm{l}$ buffer and $1.0 \mu \mathrm{l} \mathrm{M}-\mathrm{MLV}$ ) was added and mixed, reacted at $37^{\circ} \mathrm{C}$ for $2.5 \mathrm{~h}$, heated at $65^{\circ} \mathrm{C}$ for $30 \mathrm{~min}$, and $20 \mu \mathrm{l}$ cDNA was diluted to $100 \mu \mathrm{l}$ with ionized water and stored at $-20^{\circ} \mathrm{C}$. PCR reaction: GAPDH as an internal reference. Primer sequences are shown in Table I. All the primers were synthesized by Suzhou Hongxun Biotechnologies Co., Ltd. (Suzhou, China). PCR reaction conditions: pre-denaturation at $94^{\circ} \mathrm{C}$ for $3 \mathrm{~min}$, denaturation at $94^{\circ} \mathrm{C}$ for $30 \mathrm{sec}$, annealing at $60^{\circ} \mathrm{C}$ for $30 \mathrm{~min}$, extension at $72^{\circ} \mathrm{C}$ for $1 \mathrm{~min}$, elongation at $72^{\circ} \mathrm{C}$ for $10 \mathrm{~min}$, and a total of 35 cycles of amplification reaction. The manufacturer's software was used for amplification analysis, and GAPDH was used as an internal reference gene. The result was processed using $2^{-\Delta \Delta \mathrm{Cq}}(10)$.

Statistical analysis. SPSS 17.0 (Softnet Technology Co., Ltd., Tianjin, China) was used for statistical analysis. Measured data were expressed as mean \pm standard deviation (means $\pm \mathrm{SD}$ ). The t-test was used to compare measurement data between two groups. Chi-square test was used for comparison of enumeration data between the groups. ANOVA was used to compare multiple groups of means. Dunnett's test was used for the posthoc pairwise comparisons. Pearson's correlation test was used to analyze the correlation between ADAMTS-1 mRNA and CVF and TGF- $\beta 1 \mathrm{mRNA}$ in mice with chronic VMC. $\mathrm{P}<0.05$ for the difference was considered statistically significant.

\section{Results}

General conditions of mice and myocardial fibrosis. Nine mice died in the acute VMC group, and the mortality rate was 
Table I. Primers for TGF- $\beta 1$, ADAMTS- 1 and GAPDH gene sequences.

\begin{tabular}{lll}
\hline Gene name & \multicolumn{1}{c}{ Upstream primer sequences } & \multicolumn{1}{c}{ Downstream primer sequences } \\
\hline$T G F-\beta 1$ & 5'-ACCTGCAAGAC-TATCGACATGGAGCTGGTG-3' & 5'-ACCTGCAAGAC-TATCGACATGGAGCTGGTG-3' \\
ADAMTS-1 & 5'-AGCATCCCAGCATTAGGA-3' & 5'-CATGTAGGCACTGCAAGG-3' \\
GAPDH & 5'-GGTGAAGGTCGGTGTGAACG-3' & 5'-CTCGCTCCTGGAAGATGGTG-3' \\
\hline
\end{tabular}

TGF- $\beta 1$, transforming growth factor- $\beta 1$.

Table II. General information of the three groups of mice.

\begin{tabular}{|c|c|c|c|c|c|}
\hline Category & $\begin{array}{l}\text { Acute VMC } \\
\text { group }(n=41)\end{array}$ & $\begin{array}{l}\text { Chronic VMC } \\
\text { group }(n=37)\end{array}$ & $\begin{array}{c}\text { Control } \\
\text { group }(n=50)\end{array}$ & $\mathrm{F} / \chi^{2}$ & P-value \\
\hline \multicolumn{6}{|l|}{ Sex, n $(\%)$} \\
\hline Male & $26(63.41)$ & $19(51.35)$ & $34(68.00)$ & 2.568 & 0.277 \\
\hline Female & $15(36.59)$ & $18(48.65)$ & $16(32.00)$ & & \\
\hline \multicolumn{6}{|l|}{ Age, n (\%) } \\
\hline$\leq 5$ weeks & $29(70.73)$ & $23(62.16)$ & $31(62.00)$ & 1.040 & 0.595 \\
\hline$>5$ weeks & $12(29.27)$ & $14(37.84)$ & $19(38.00)$ & & \\
\hline \multicolumn{6}{|l|}{ Body mass, n (\%) } \\
\hline$\leq 19 \mathrm{~g}$ & $25(60.98)$ & $26(70.27)$ & $29(58.00)$ & 1.426 & 0.490 \\
\hline$<19 \mathrm{~g}$ & $16(39.02)$ & $11(29.73)$ & $21(42.00)$ & & \\
\hline Indoor temperature $\left({ }^{\circ} \mathrm{C}\right)$ & $24.09 \pm 1.23$ & $24.16 \pm 1.29$ & $24.56 \pm 1.46$ & 1.642 & 0.197 \\
\hline Indoor humidity (\%) & $55.29 \pm 2.15$ & $56.16 \pm 2.31$ & $55.28 \pm 1.94$ & 2.245 & 0.110 \\
\hline
\end{tabular}

VMC, viral myocarditis.

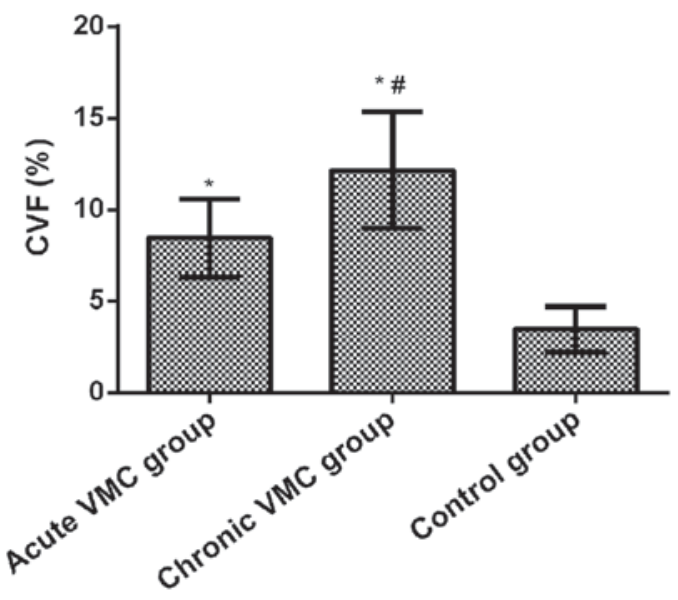

Figure 1. Comparison of myocardial CVF (\%) results in the acute and chronic VMC and control groups. The picrosirius red collagen staining results showed that compared with the control group, the CVF in the myocardial tissue of the acute VMC group was significantly increased ( $\mathrm{p}<0.001)$. The increase of CVF in myocardial tissue of the chronic VMC group was most obvious $(\# \mathrm{p}<0.001)$. CVF, collagen volume fraction; VMC, viral myocarditis.

$18.00 \%$ (9/50). Thirteen mice died in the chronic VMC group, and the mortality rate was $26.00 \%(13 / 50)$. None of the mice in the control group died. The sex, age, body weight, indoor temperature and indoor humidity of the three groups of mice had no effect on this experiment ( $p>0.05)$ (Table II). The myocardial tissue of mice was stained with picrosirius acid red collagen after the calculation. It was observed that compared with the control group, the CVF of the myocardial tissue in the acute VMC group was significantly increased, and the increase of CVF in the myocardial tissue of the chronic VMC group was the most obvious $(\mathrm{p}<0.001)$ (Fig. 1).

Relative expression of TGF- $\beta 1$ mRNA in mouse myocardium. The relative expression levels of TGF- $\beta 1$ mRNA in myocardial tissue of the acute and chronic VMC and control groups were $1.364 \pm 0.564,2.158 \pm 1.086$, and $0.692 \pm 0.470$, respectively. Compared with the control group, the relative expression of TGF- $\beta 1$ mRNA in myocardial tissue of mice in the acute VMC group was significantly increased $(\mathrm{t}=6.201, \mathrm{p}<0.001)$. The relative expression of TGF- $\beta 1$ mRNA in myocardial tissue of the chronic VMC group was significantly increased $(t=8.538, p<0.001)$; the relative expression of TGF- $\beta 1$ mRNA in myocardial tissue of the chronic VMC group was significantly higher than that of the acute VMC group $(\mathrm{t}=4.109, \mathrm{p}<0.001)$. The difference between the three groups was statistically significant $(\mathrm{F}=43.340, \mathrm{p}<0.001)$ (Fig. 2).

Relative expression of ADAMTS-1 mRNA in mouse myocardium. The relative expression levels of ADAMTS-1 mRNA in myocardial tissue of the acute and chronic VMC and control groups were $2.697 \pm 1.323,3.781 \pm 1.587$, and 


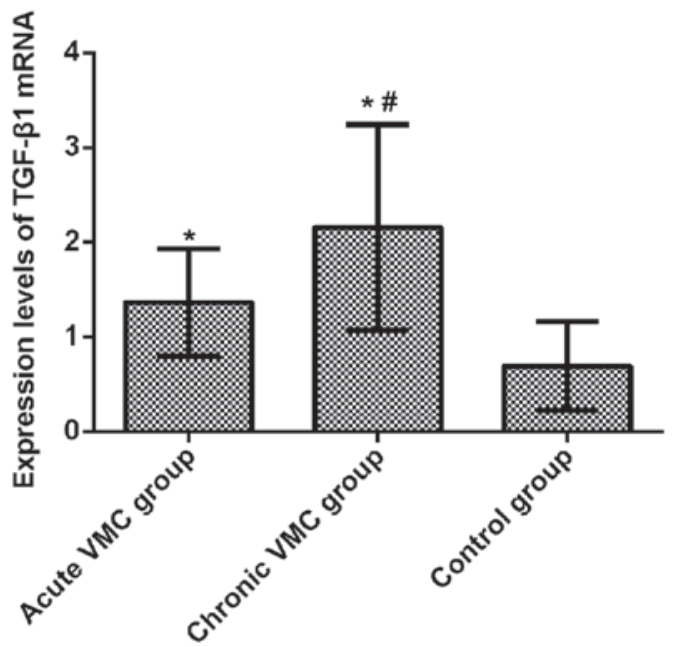

Figure 2. Comparison of the relative expression levels of TGF- $\beta 1 \mathrm{mRNA}$ in myocardial tissue of the acute and chronic VMC and control groups. The results of RT-qPCR showed that compared with the control group, the relative expression of TGF- $\beta 1$ mRNA in the myocardium of the acute VMC group was significantly increased $(\mathrm{t}=6.201, \mathrm{p}<0.001)$. The relative expression of $\beta 1 \mathrm{mRNA}$ was significantly increased $(\mathrm{t}=8.538, \mathrm{p}<0.001)$. The relative expression of TGF- $\beta 1$ mRNA in myocardial tissue of the chronic VMC group was significantly higher than that of the acute VMC group ( $\mathrm{t}=4.109$, $\mathrm{p}<0.001)$. There was a statistically significant difference between the two groups $(\mathrm{F}=43.340, \mathrm{p}<0.001)$. ${ }^{*} \mathrm{P}<0.001$, compared with the control group; ${ }^{\#} \mathrm{p}<0.001$, compared with the acute VMC group. TGF- $\beta 1$, transforming growth factor- $\beta 1$; VMC, viral myocarditis.

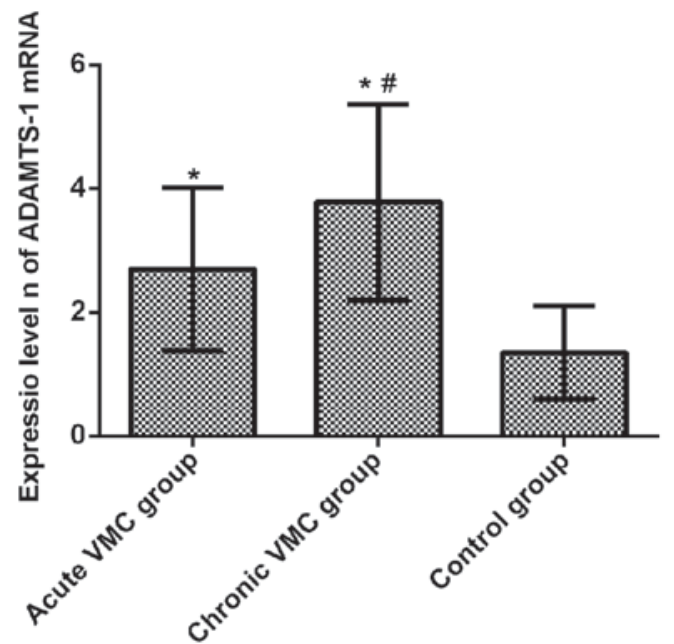

Figure 3. Comparison of the relative expression of ADAMTS-1 mRNA in myocardial tissue of the acute and chronic VMC and control groups. RT-qPCR results showed that compared with the control group, the relative expression of ADAMTS-1 mRNA in the myocardial tissue of the acute VMC group was significantly increased $(t=6.094, \mathrm{p}<0.001)$. In the VMC group, the relative expression of ADAMTS-1 mRNA was significantly increased $(\mathrm{t}=9.488, \mathrm{p}<0.001)$. The relative expression of ADAMTS-1 mRNA in myocardial tissue of the chronic VMC group was significantly higher than that of the acute VMC group $(\mathrm{t}=3.288, \mathrm{p}<0.001)$. There was a statistically significant difference between the two groups $(\mathrm{F}=42.550, \mathrm{p}<0.001)$. ${ }^{\text {}} \mathrm{P}<0.001$, compared with the control group; ${ }^{\#} \mathrm{p}<0.001$, compared with the acute VMC group. VMC, viral myocarditis.

$1.349 \pm 0.757$, respectively. Compared with the control group, the relative expression of ADAMTS-1 mRNA in the myocardial tissue of the acute VMC group was significantly increased $(\mathrm{t}=6.094, \mathrm{p}<0.001)$. The relative expression of ADAMTS-1

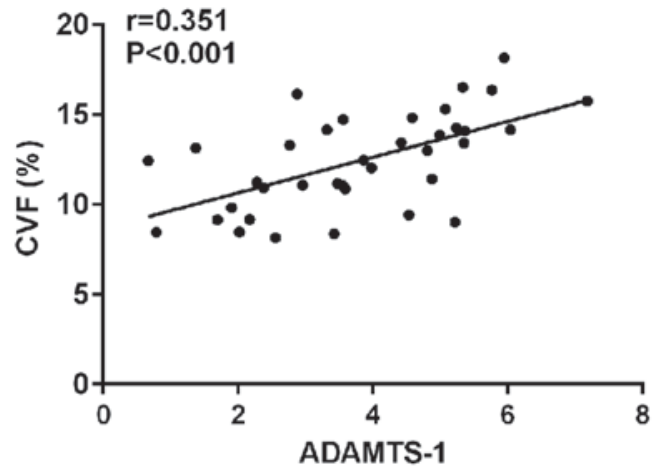

Figure 4. Correlation of ADAMTS-1 mRNA with CVF in myocardial tissue of the chronic VMC group. Pearson's correlation test results showed that the relative expression of ADAMTS-1 mRNA was positively correlated with CVF in the myocardial tissue of mice $(r=0.351, p<0.01)$. CVF, collagen volume fraction; VMC, viral myocarditis.

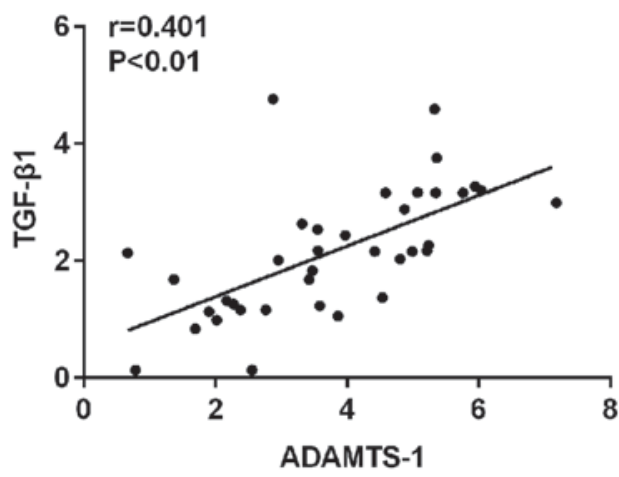

Figure 5. Correlation of ADAMTS-1 mRNA with TGF- $\beta 1$ mRNA in myocardial tissue of the chronic VMC group. Pearson's correlation test results showed that the relative expression of ADAMTS- 1 mRNA was positively correlated with TGF- $\beta 1$ mRNA in the mouse myocardium $(r=0.401, p<0.01)$. TGF- $\beta 1$, transforming growth factor- $\beta 1$; VMC, viral myocarditis.

mRNA in the myocardial tissue of the chronic VMC group was significantly increased $(t=9.488, p<0.001)$; the relative expression of ADAMTS-1 mRNA in myocardial tissue of the chronic VMC group was significantly higher than that of the acute VMC group $(\mathrm{t}=3.288, \mathrm{p}<0.001)$. The difference between the three groups was statistically significant $(\mathrm{F}=42.550$, p $<0.001$ ) (Fig. 3).

Correlation of ADAMTS-1 mRNA with CVF and TGF- $\beta 1$ $m R N A$ in myocardium of the chronic VMC group. Pearson's correlation test results showed that the relative expression of ADAMTS-1 mRNA was positively correlated with CVF in the myocardial tissue of mice $(r=0.351, p<0.01)$, and positively correlated with TGF- $\beta 1$ mRNA in the mouse myocardium $(r=0.401, p<0.01)($ Figs. 4 and 5).

\section{Discussion}

There will be a common pathological change in a variety of heart diseases when they develop to a certain extent, namely myocardial fibrosis (11). Myocardial fibrosis is an adaptive reaction in the body, which is the pathological and physiological reaction process of ventricular whole body compensation and lesion repair. It is mainly characterized by 
the cardiac fibroblast hyperproliferation, abnormal distribution and arrangement disorder of various types of collagen (12). Myocardial fibrosis in the normal tissue of the myocardium showed a large number of deposition of collagen fibers, and myocardial collagen composition changed, increasing collagen concentration, which is closely related to collagen metabolism abnormalities and other factors of extracellular matrix components of the heart (13). Myocardial fibrosis is one of the manifestations of myocardial remodeling, and studies have shown that cell-level damage can alter the original material and heart morphology, resulting in myocardial cell remodeling and myocardial collagen network remodeling (14).

Excessive myocardial fibrosis is the pathological basis of many complications and disease evolution of VHD. In the acute phase of viral infection, collagen hyperplasia is a manifestation of compensatory fibrosis. The simultaneous presence of reactive fibrosis and repair fibrosis in chronic and convalescent VHD is a major factor affecting cardiac function $(15,16)$. TGF- $\beta 1$ is one of the cytokines involved in the regulation of myocardial fibrosis, and can stimulate the ECM protein gene to induce myocardial fibrosis (17). TGF- $\beta 1$ can promote the transformation of myocardial tissue collagen gene and cardiac fibroblasts, promote myocardial synthesis of extracellular matrix, increase myocardial collagen deposition, resulting in myocardial fibrosis, which can be used as a growth factor to predict myocardial fibrosis $(18,19)$. ADAMTS-1 is mainly derived from colon cancer cells, and is a tumor malignant metamorphosis specific gene. Its protein molecules have a secretory function, and can be secreted into the ECM to participate in the regulation of ECM proteins. It plays an important role in human growth and development, urogenital organ function, and physiological and pathological processes of inflammation (20). Dubey et al (21) showed that ADAMTS-1 may activate and cleave MMP13 and MMP14, thereby reducing the degradation of ECM proteins by matrix metalloproteinases, and ultimately causing abnormal follicle excretion. The results of this study showed that compared with the control group, the relative expression of TGF- $\beta 1$ and ADAMTS-1 in the myocardial tissue of mice with acute VMC was significantly increased. With the progress of the disease, the TGF- $\beta 1$ in the myocardial tissue of mice with chronic VMC was significantly increased. The relative expression levels of ADAMTS-1 and ADAMTS-1 were significantly higher than those of the acute VMC group, suggesting that both of them may be involved in the occurrence and development of myocardial fibrosis. RT-qPCR was used to detect TGF- $\beta 1$ mRNA and ADAMTS- 1 mRNA in acute and chronic phases. The expression of TGF- $\beta 1 \mathrm{mRNA}$ and ADAMTS-1 mRNA were gradually increased with the progress of the disease. The Pearson's correlation test showed that ADAMTS-1 mRNA was positively correlated with CVF and TGF- $\beta 1$ mRNA, suggesting that ADAMTS-1 mRNA may play a role in promoting myocardial fibrosis during the development of VHD. This is similar to the study of Mittaz et al (22). ADAMTS-1 plays an important role in the occurrence and development of renal interstitial fibrosis by participating in the regulation of ECM, promoting renal interstitial fibrosis. $\mathrm{Ng}$ et al (23) showed that TGF- $\beta 1$ can differentially regulate the expression of ADAMTS-1 mRNA in primary cultures of decidual stromal cells, but this study failed to explore the regulatory mechanism between them, which still needs further verification.

In this study, purebred inbred Balb/c mice were selected as animal models, and the modeling was simple and reliable. The injection of CVB3 Nancy strain into the mouse infection model was able to better simulate the environmental changes in the body and the clinical pathology of human myocarditis. The performance is similar, ensuring the reliability of the experiment. This study did not analyze the regulation mechanism of ADAMTS-1 in myocardial tissue of the acute and chronic VMC groups, and did not do in vitro experiments to provide more theoretical support. Therefore, it is hoped that in the next study, the regulation mechanism of ADAMTS-1 in myocardium of VMC myofibrotic animal model can be further discussed.

In summary, ADAMTS-1 is involved in the occurrence and development of myocardial fibrosis, and is positively correlated with CVF and TGF- $\beta 1$. It may play a role in promoting myocardial fibrosis during the development of VHD, and can be used as a predictor of myocardial fibrosis.

\section{Acknowledgements}

Not applicable.

\section{Funding}

No funding was received.

\section{Availability of data and materials}

The datasets used and/or analyzed during the present study are available from the corresponding author on reasonable request.

\section{Authors' contributions}

$\mathrm{HL}$ and $\mathrm{YZ}$ wrote the manuscript and established the animal model. WS and JL determined the myocardial collagen in mice. HL, YZ and JX were responsible for RT-qPCR. All authors read and approved the final manuscript.

\section{Ethics approval and consent to participate}

The study was approved by the Ethics Committee of Yidu Central Hospital of Weifang (Weifang, China).

\section{Patient consent for publication}

Not applicable.

\section{Competing interests}

The authors declare that they have no competing interests.

\section{References}

1. Yuan J, Liao YH, Jin XJ, Wang ZH, Yu M, Chen RZ, Xu DJ, Wei J, Wan J, Zhao DC, et al: Continued elevation of plasma IL-4 and IL-17 predicts the progression from viral myocarditis to dilated cardiomyopathy. Eur Heart J 38 (suppl 1): P5143, 2017. 
2. Clemente-Casares X, Hosseinzadeh S, Barbu I, Dick SA, Macklin JA, Wang Y, Momen A, Kantores C, Aronoff L, Farno M, et al: A CD103 ${ }^{+}$conventional dendritic cell surveillance system prevents development of overt heart failure during subclinical viral myocarditis. Immunity 47: 974-989.e8, 2017.

3. Becher PM, Gotzhein F, Klingel K, Escher F, Blankenberg S, Westermann D and Lindner D: Cardiac function remains impaired despite reversible cardiac remodeling after acute experimental viral myocarditis. J Immunol Res 2017: 6590609, 2017.

4. Jin SA, Lim BK, Kim SK, Seo HJ, Seo BS, Kwon HJ, Seong SW, Jeong JO and Seong IW: Identification of serum apurinic/apyrimidinic endonuclease $1 /$ redox effector factor-1 (APE1/Ref-1) in mouse model of viral myocarditis; implication of a novel biomarker for myocarditis. Eur Heart J 38 (suppl 1): 3515, 2017.

5. Lurz JA, Luecke C, Lang D, Besler C, Rommel KP, Klingel K, Kandolf R, Adams V, Schöne K, Hindricks G, et al: CMR-derived extracellular volume fraction as a marker for myocardial fibrosis: The importance of coexisting myocardial inflammation. JACC Cardiovasc Imaging 11: 38-45, 2018.

6. Zhou B and Yu JW: A novel identified circular RNA, circRNA_010567, promotes myocardial fibrosis via suppressing miR-141 by targeting TGF- $\beta 1$. Biochem Biophys Res Commun 487: 769-775, 2017.

7. Tola EN, Karatopuk DU, Koroglu N, Ergin M and Oral HB: Follicular ADAMTS-1 and aggrecan levels in polycystic ovary syndrome. J Assist Reprod Genet 34: 811-816, 2017.

8. Tang H, Lee M, Kim EH, Bishop D and Rodgers GM: siRNA-knockdown of ADAMTS-13 modulates endothelial cell angiogenesis. Microvasc Res 113: 65-70, 2017.

9. Rittié L: Method for picrosirius red-polarization detection of collagen fibers in tissue sections. Methods Mol Biol 1627: 395-407, 2017.

10. Livak KJ and Schmittgen TD: Analysis of relative gene expression data using real-time quantitative PCR and the 2(-Delta Delta C(T)) method. Methods 25: 402-408, 2001.

11. Schelbert EB, Fridman Y, Wong TC, Abu Daya H, Piehler KM, Kadakkal A, Miller CA, Ugander M, Maanja M, Kellman P, et al: Temporal relation between myocardial fibrosis and heart failure with preserved ejection fraction: Association with baseline disease severity and subsequent outcome. JAMA Cardiol 2: 995-1006, 2017.

12. Francone M: Role of cardiac magnetic resonance in the evaluation of dilated cardiomyopathy: Diagnostic contribution and prognostic significance. ISRN Radiol 2014: 365404, 2014.

13. Chen CY, Su MY, Lin LY, Tsai CT, Wang YC, Lin YH, Lee JK, Wu CK, Juang JM, Huang JJ, et al: Congenital hypertrophic cardiomyopathy with genetic mutations is highly associated with left ventricular myocardial fibrosis and larger right ventricle (TW-HCM study). Eur Heart J 38 (suppl_1): 4097, 2017.
14. Fang L, Ellims AH, Beale AL, Taylor AJ, Murphy A and Dart AM: Systemic inflammation is associated with myocardial fibrosis, diastolic dysfunction, and cardiac hypertrophy in patients with hypertrophic cardiomyopathy. Am J Transl Res 9: 5063-5073, 2017.

15. Spartera M,Damascelli A,Mozes F, De Cobelli F and La Canna G: Three-dimensional speckle tracking longitudinal strain is related to myocardial fibrosis determined by late-gadolinium enhancement. Int J Cardiovasc Imaging 33: 1351-1360, 2017.

16. Arbustini E, Favalli V and Narula N: Extracellular volume in dilated cardiomyopathy: Interstitial fibrosis and more? JACC Cardiovasc Imaging 11: 60-63, 2018.

17. Guo Y, Gupte M, Umbarkar P, Singh AP, Sui JY, Force T and $\mathrm{Lal} \mathrm{H}$ : Entanglement of GSK-3 $\beta, \beta$-catenin and TGF- $\beta 1$ signaling network to regulate myocardial fibrosis. J Mol Cell Cardiol 110: 109-120, 2017.

18. Hong SK, Choo EH, Ihm SH, Chang K and Seung KB: Dipeptidyl peptidase 4 inhibitor attenuates obesity-induced myocardial fibrosis by inhibiting transforming growth factor- $\beta 1$ and Smad2/3 pathways in high-fat diet-induced obesity rat model. Metabolism 76: 42-55, 2017.

19. Dzeshka MS, Appadoo K, Shantsila E, Snezhitskiy VA and Lip GYH: Increased evidence of left ventricular myocardial fibrosis in patients with paroxysmal atrial fibrillation and sinus node dysfunction. Eur Heart J 38: P1720, 2017.

20. Salvarani N, Maguy A, De Simone SA, Miragoli M, Jousset F and Rohr S: TGF- $\beta 1$ (transforming growth factor- $\beta 1$ ) plays a pivotal role in cardiac myofibroblast arrhythmogenicity. Circ Arrhythm Electrophysiol 10: e004567, 2017.

21. Dubey D, McRae PA, Rankin-Gee EK, Baranov E, Wandrey L, Rogers S and Porter BE: Increased metalloproteinase activity in the hippocampus following status epilepticus. Epilepsy Res 132: 50-58, 2017.

22. Mittaz L, Ricardo S, Martinez G, Kola I, Kelly DJ, Little MH, Hertzog PJ and Pritchard MA: Neonatal calyceal dilation and renal fibrosis resulting from loss of Adamts-1 in mouse kidney is due to a developmental dysgenesis. Nephrol Dial Transplant 20: 419-423, 2005.

23. Ng YH, Zhu H, Pallen CJ, Leung PC and MacCalman CD: Differential effects of interleukin-1beta and transforming growth factor-betal on the expression of the inflammation-associated protein, ADAMTS-1, in human decidual stromal cells in vitro. Hum Reprod 21: 1990-1999, 2006. International (CC BY-NC-ND 4.0) License. 